\title{
EVALUASI FAKTOR TRANSFER PELATIHAN TERHADAP KINERJA DEPARTEMEN PEMELIHARAAN
}

\section{EVALUATION OF TRAINING TRANSFER FACTORS ON MAINTENANCE PERFORMANCE DEPARTMENT}

\section{Fatoni $^{1}$}

1Jurusan Teknik Industri, Fakultas Teknik, Universitas Indraprasta PGRI, Jl. Nangka No. 58 C (TB. Simatupang), Kel. Tanjung Barat, Kec. Jagakarsa, Jakarta Selatan, Indonesia 12530

*Email: fatoni.id@gmail.com

\begin{tabular}{ll} 
INFORMASI ARTIKEL & ABSTRAK \\
\hline Histori Artikel & Bagian maintenance yang merupakan salah satu bagian operasional \\
- Artikel dikirim & yang memberikan peranan penting dalam pengelolaan modal \\
$22 / 10 / 2020$ & industri. Kinerja maintenance akan optimal apabila pada proses \\
- Artikel diperbaiki & pelaksanaanya dilakukan oleh personil yang mempunyai tingkat \\
$13 / 11 / 2020$ & kemampuan dan keterampilan yang memadai. Untuk mencapai \\
- Artikel diterima & keunggulan dalam maintenance, karyawan harus dibekali pelatihan \\
$15 / 11 / 2020$ & dan pengembangan agar mereka terampil dalam melakukan \\
- Artikel dipublish & pekerjaannya. Tujuan dari penelitian untuk menilai hubungan \\
$30 / 11 / 2020$ & training dengan maintenance, utamanya dalam hal memberikan \\
& penilaian tentang faktor-faktor transfer training terhadap \\
& pencapaian efektivitas kinerja maintenance serta memberikan \\
& informasi dan rekomendasi terkait penentuan skala prioritas faktor- \\
& faktor dalam pelaksanaan training di departemen maintenance. Data \\
& diambil dari beberapa perusahaan dengan bidang industri yang \\
& berbeda dan menggunakan beberapa metode statistik untuk \\
& mendapatkan kesimpulan dari penelitian yang telah dilakukan. \\
& Hasil penelitian ini mengungkapkan bahwa faktor motivasi dan \\
& kepribadian peserta training merupakan faktor yang paling \\
& berpengaruh terhadap keberhasilan proses training di dalam \\
& sebuah organisasi maintenance.
\end{tabular}

Kata Kunci: Maintenance, Kinerja, Transfer Training.

\section{ABSTRACT}

The maintenance section is one of the operational parts that play an important role in the management of industrial capital. Maintenance performance will be optimal if the implementation process is carried out by personnel who have adequate levels of capability and skills. To achieve excellence in maintenance, employees must be provided with training and development so that they are skilled at doing their job. The purpose of this study is to assess the relationship between training and maintenance, especially in terms of providing an assessment of the factors of transfer training on the effectiveness of maintenance performance and providing information and recommendations 
regarding the priority scale of factors in the implementation of training in the maintenance department The data is taken from several companies with different industrial fields and uses several statistical methods to get conclusions from the research that has been done. The results of this study reveal that the motivation and personality factors of the training participants are the factors that most influence the success of the training process in a maintenance organization.

\section{Keywords: Maintenance, Performance, Transfer Training}

\section{Pendahuluan}

Maintenance merupakan fungsi kunci dalam mempertahankan keuntungan jangka panjang pada organisasi [1] Maintenance telah menjadi bagian tersendiri yang mengurusi masalah teknis dan bertanggung jawab terhadap kesiapan peralatan [2]. Peranan bagian maintenance yang sangat penting ini, diiringi dengan naiknya penelitian dan perhatian dari para ahli dan praktisi yang mempelajari tentang pengukuran kinerja maintenance. Menurut Au-Yong et al [3], mengukur kinerja maintenance merupakan sebuah penilaian yang membantu dalam mengidentifikasi kelebihan dan kekurangan aktivitas maintenance. Kinerja dari bagian maintenance sangat dipengaruhi oleh kompetensi anggotanya. Semakin tinggi tingkat pengetahuan dan ketrampilan yang dimiliki, semakin memudahkan bagian maintenance dalam mencapai target yang telah ditetapkan. Salah satu upaya untuk meningkatkan level kompetensi karyawan maintenance adalah memberikan reguler pelatihan agar kemampuan yang sudah dimiliki semakin terasah dan bertambahnya wawasan baru menyesuaikan dengan perkembangan teknologi. Pelatihan merupakan salah satu bagian yang berkontribusi terhadap organisasi untuk mempersiapkan perubahan dan melengkapi seluruh karyawannya dengan keterampilan tambahan sehingga memungkinkan mereka mendapatkan peran yang baru dalam pekerjaan [4]. Pendapat ini diperkuat oleh Noe [5], bahwa latihan akan memfasilitasi pembelajaran bagi anggota organisasi tentang keterampilan, pengetahuan, atau perilaku yang berperan dalam kesuksesan kinerjanya.

Maintenance suatu aktivitas atau kegiatan yang berfungsi untuk mengembalikan kondisi peralatan kembali ke kondisi seperti semula, agar peralatan tetap bisa beroperasi sesuai fungsi awalnya [6]. Seiring berjalannya waktu, peralatan operasional akan menurun kinerjanya disebabkan oleh keausan, umur pakai dan korosi. Bagian maintenance berfungsi untuk mengembalikan semua fungsi peralatan tersebut dengan berbagai macam metode sehingga produktivitasnya tetap terjaga. Pentingnya peran dari bagian maintenance ini membuat banyak munculnya penelitian empiris untuk menyelidiki tentang sistem manajemen kinerja pada proses maintenance [7].

Mengukur kinerja maintenance dapat diartikan sebagai proses pengukuran nilai yang diciptakan oleh investasi pada maintenance, untuk memenuhi persyaratan yang telah ditetapkan organisasi, dilihat dari strategi pada keseluruhan perspektif bisnis. Pengukuran kinerja maintenance berfungsi untuk melakukan revisi dan evaluasi terhadap kebijakan dan teknik pemeliharaan yang digunakan, evaluasi alokasi sumber daya, dan untuk memahami efek dari maintenance terhadap fungsi-fungsi yang lain.

Tsang et al [8] menjelaskan secara umum fokus pengukuran kinerja pada bagian maintenance dibagi menjadi tiga kategori utama

A. Mengukur kinerja peralatan. Contoh umum kinerja ini adalah availability, reliability, dan overall equipment effectiveness (OEE).

B. Mengukur biaya operasional maintenance. Misalnya biaya tenaga kerja dan biaya penggunaan material / spare part. 
C. Mengukur kinerja proses maintenance. Misalnya mengukur rasio pekerjaan terencana dan pekerjaan yang tidak terencana, kesesuaian terhadap jadwal yang sudah ditetapkan.

Dari sekian banyak metode yang digunakan untuk mengukur kinerja maintenance, pengukuran OEE dianggap sebagai metode yang paling efektif untuk mengukur kinerja maintenance secara keseluruhan [9]. OEE sebagai sebuah pendekatan untuk mengevaluasi kemajuan yang dicapai dalam inisiatif perbaikan yang juga merupakan bagian dari idenya tentang filosofi Total Productive Maintenance. Tiga hal utama yang merupakan kunci pengukuran kinerja yang dikombinasikan menjadi metrik gabungan dalam perhitungan OEE adalah availability (A), performance rate $(\mathrm{P})$, dan quality rate $(\mathrm{Q})$. Perhitungan terhadap ketiga hal tersebut ditampilkan dalam gambar 1.

\begin{tabular}{|c|c|c|c|c|}
\hline \multicolumn{5}{|c|}{ Calculation of Overall Equipment Effectiveness (OEE) } \\
\hline \multicolumn{4}{|l|}{$\begin{array}{l}\text { Planned } \\
\text { production time }\end{array}$} & \\
\hline \begin{tabular}{|l|} 
Actual running \\
time
\end{tabular} & & & $\left|\begin{array}{ll}1 & \text { Unplanned } \\
\text { stop } & \text { Setup }\end{array}\right| \rightarrow$ & $\begin{array}{l}\text { Availability }= \\
\frac{\text { Planned production time - Down time }}{\text { Planned production time }}: 100 \%\end{array}$ \\
\hline $\begin{array}{l}\text { Net operating } \\
\text { time }\end{array}$ & & \multirow{2}{*}{$\begin{array}{|ll|}3 & \text { Idling \& minor } \\
& \text { stoppage } \\
4 & \text { Reduce speed } \\
\end{array}$} & & $\begin{array}{l}\text { Operational Efficiency }= \\
\text { Design Ceyle Time XProd. Amount } \\
\text { : 100\% }\end{array}$ \\
\hline $\begin{array}{l}\text { Valuable- } \\
\text { operating time }\end{array}$ & \begin{tabular}{|l}
5 Defect in \\
process \\
6 Reduce yield
\end{tabular} & & & $\begin{array}{l}\text { Quality Rate }= \\
\frac{\text { Produced Amount - Defect Amount }}{\text { Produced Amount }}=100 \%\end{array}$ \\
\hline
\end{tabular}

Sumber: Nakajima 1988

Gambar 1. Perhitungan OEE.

Pengukuran kinerja merupakan alat manajemen untuk mengukur arah dan kecepatan perubahan yang dilakukan oleh organisasi menuju ke produktivitas optimal. Pencapaian kinerja maintenance sangat bergantung pada tingkat pengetahuan dan kemampuan dari personel maintenance itu sendiri. Kurangnya pengetahuan dan tidak memadainya pelatihan bagi para pelaku di maintenance termasuk diantara alasan gagalnya maintenance [10]. Pelatihan dianggap bisa menjadi sarana bagi organisasi untuk bisa mengarahkan anggotanya menjadi tenaga kerja yang terampil dan memiliki etos kerja yang tinggi. Oleh karena itu, penelitian ini mencoba mengkaji korelasi dari faktor-faktor dalam proses transfer pelatihan terhadap kinerja bagian maintenance.

Pelatihan adalah usaha terencana dari organisasi untuk memfasilitasi karyawannya dalam meningkatkan pengetahuan, keterampilan, dan perilaku dalam mendukung dalam kesuksesan kinerjanya [5]. Sementara itu Rana [11], mendefinisikan pelatihan sebagai aktivitas yang terencana, sistematis dan menghasilkan peningkatan dalam level keterampilan, pengetahuan dan kompetensi yang diperlukan dalam menghasilkan kinerja yang lebih efektif. Pentingnya pelatihan sejalan dengan perubahan global yang membuat lingkungan organisasi menjadi lebih kompetitif dan mengharuskan organisasi mempersiapkan hal ini secara berkelanjutan [12].

Disamping itu, pelatihan memainkan peran kunci dalam memastikan bahwa karyawan bisa bekerja sama secara lebih efektif satu sama lain.

Keberhasilan dalam proses pelatihan ditentukan oleh faktor-faktor kunci, yaitu faktor transfer pelatihan yang harus dijadikan perhatian oleh organisasi. Transfer pelatihan didefinisikan sebagai sejauh mana peserta pelatihan mampu secara efektif menerapkan 
pengetahuan, keterampilan, dan perilaku yang diperoleh selama pelatihan terhadap pekerjaan [13]. Teori ini diperkuat dengan membuat sebuah model transfer pelatihan seperti terlihat pada gambar 2.

Terdapat tiga faktor utama yang sangat berpengaruh dalam keberhasilan proses transfer pelatihan, yaitu karakteristik peserta pelatihan (training characteristic). Desain pelatihan (training design) dan lingkungan kerja (work environment). Dalam penelitian ini, detail faktor transfer pelatihan dikupas lebih terperinci, tidak hanya melihat dari sisi faktor utama, namun juga melihat lebih detail pada tiap-tiap sub-faktornya, untuk nantinya dikorelasikan dengan hasil yang ingin dicapai. Disamping faktor-faktor transfer pelatihan yang disebutkan pada gambar 2, penelitian lain juga menyatakan bahwa ada faktor tambahan lain yang perlu menjadi pertimbangan dalam implementasi proses pelatihan transfer [14][15][16]. Hal tersebut dirangkum dan ditampilkan sebagai factor tambahan transfer pelatihan dan ditampilkan pada gambar 3 [13].

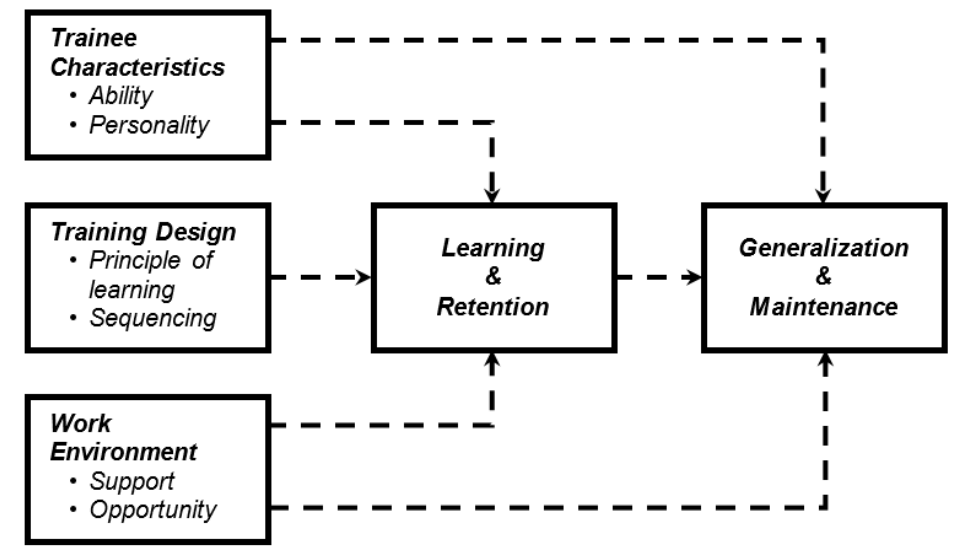

Gambar 2. Model proses transfer pelatihan.

Secara umum variabel dalam penelitian dibagi menjadi variabel bebas dan variabel terikat. Berdasarkan tinjauan pustaka yang telah diuraikan mengenai faktor transfer pelatihan ditetapkan sebagai variabel bebas dan variabel terikatnya adalah kinerja maintenance.

Hasil dari penelusuran beberapa literatur menunjukkan bahwa transfer pelatihan berperan sebagai variabel bebas memiliki 10 faktor, sementara itu untuk variabel terikatnya yaitu kinerja maintenance menggunakan indikator Overall Equipment Effectiveness (OEE), dikarenakan OEE merupakan metode yang dianggap sangat kuat dalam mengukur dan mengevaluasi efektifitas kinerja individual peralatan maupun proses maintenance secara keseluruhan [9][17][18].

\section{Metode}

Metode kuesioner digunakan untuk memperoleh data pada penelitian ini. Seleksi pemilihan responden berasal perusahaan dari beberapa jenis industri. Total 120 data valid hasil kuesioner berhasil dikumpulkan oleh penulis. Profil dari responden ditunjukkan pada tabel 1. Desain kuesioner dibuat berdasarkan observasi dan kutipan dari paper, buku, jurnal dan literatur. Berbagai macam isu yang mencakup kinerja maintenance, pelatihan, ekspektasi dari pelatihan maintenance dan keuntungan yang didapatkan ketika maintenance berhasil menyelenggarakan pelatihan. Penilain semua variabel pelatihan dan kinerja maintenance dari kuesioner menggunakan skala Likert dengan range dari 1 (sangat setuju) sampai 5 (sangat tidak setuju). 


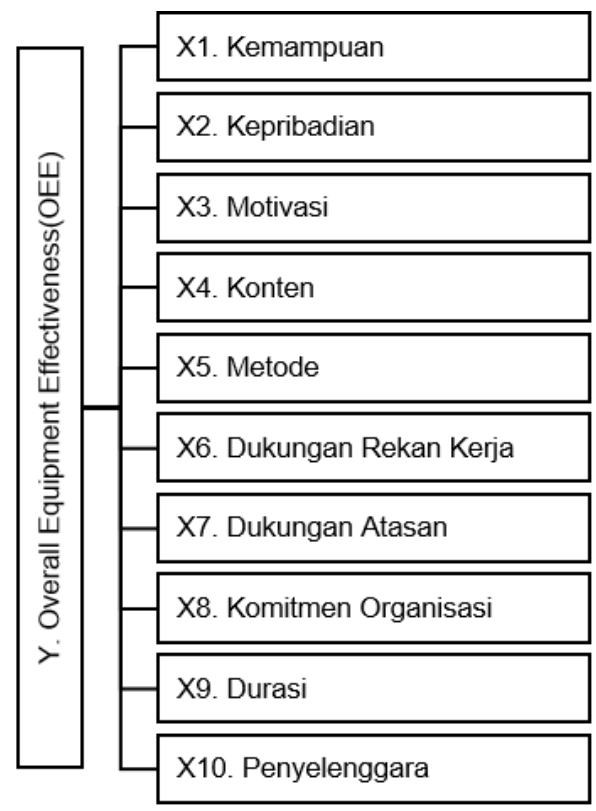

Gambar 3. Hubungan antara faktor pelatihan dan kinerja maintenance.

Metodologi penelitian bertujuan untuk mendapatkan konsep penelitian yang berisi tahapantahapan sistematis yang digunakan dalam melakukan penelitian ini.

A. Membuat kuesioner kemudian didistribusikan dengan sasaran responden personel bagian maintenance. Responden berasal dari unit kerja maintenance di beberapa perusahaan, mulai dari level teknisi atau mekanik sampai dengan level manajer.

B. Analisis faktor digunakan untuk menguji validitas dari variabel penelitian.

C. Analisis korelasi digunakan berdasarkan asumsi hubungan yang diusulkan antara pelatihan dan kinerja pemeliharaan, pengujian pengukuran hubungan variabel menggunakan Pearson Correlation.

D. Menggunakan Multiple Linear Regression untuk menganalisa pengaruh dari variabel bebas (faktor pelatihan) terhadap variabel terikat (kinerja maintenance).

Untuk memastikan bahwa hasil dari kinerja maintenance dipengaruhi oleh pelatihan yang efektif, sangat penting untuk berhati-hati dalam melakukan observasi dan mengutip perbedaan antara faktor pelatihan dan parameter kinerja maintenance. Berdasarkan kajian pustaka yang telah dilakukan, sepuluh faktor pelatihan telah ditentukan menjadi variabel bebas (X1, X2, X3, X4, $\mathrm{X} 5, \mathrm{X6}, \mathrm{X7}, \mathrm{X} 8, \mathrm{X} 9$ dan X10). Sementara itu variabel terikat (Y) yaitu OEE digunakan sebagai indikator kinerja maintenance.

Tabel 1. Jenis industri responden.

\begin{tabular}{lll}
\hline Industri & Jumlah Responden & $\%$ Kumulatif \\
\hline Manufaktur & 46 & $38 \%$ \\
Pertambangan & 45 & $38 \%$ \\
Oil \& Gas & 16 & $13 \%$ \\
Penerbangan & 9 & $8 \%$ \\
Transportasi \& Logistik & 4 & $3 \%$ \\
\hline Total & 120 & $100 \%$ \\
\hline
\end{tabular}

Tabel 2. Jabatan responden dalam organisasi maintenance. 


\begin{tabular}{lll}
\hline Jabatan & $\begin{array}{l}\text { Jumlah } \\
\text { Responden }\end{array}$ & $\begin{array}{l}\% \\
\text { Kumulatif }\end{array}$ \\
\hline Manager & 11 & $9 \%$ \\
Assistant & 10 & $8 \%$ \\
Manager & & $21 \%$ \\
Supervisor & 25 & $28 \%$ \\
Leader & 33 & $34 \%$ \\
Mekanik & 41 & $100 \%$ \\
\hline Total & 120 & \\
\hline
\end{tabular}

Gambar 2 menunjukkan hubungan antar variabel bebas (factor transfer training) dan variabel terikat (OEE). Klasifikasi variabel dependen dan independen telah diperiksa secara kritis dan diselesaikan melalui tinjauan literatur yang luas [8][19][20][21].

\section{Hasil dan Pembahasan}

3.1 Pengujian validitas dan reliabilitas.

Untuk menguji ketepatan atau ketelitian instrumen dalam mengukur pengaruh pelatihan terhadap kinerja maintenance dilakukan dengan menggunakan metode analisis faktor. Sedangkan untuk menguji reliabilitas yaitu konsistensi kuesioner diukur dengan menggunakan koefisien alpha Cronbach. Hasil validitas dan reliabilitas disajikan pada tabel 3. Sebagaimana ditunjukkan pada tabel 3, hasil pengukuran Kaiser-Meyer-Olkin Measure of Sampling Adequacy (KMO-MSA) untuk seluruh variabel lebih besar dari 0,5 dan nilai signifikansi kurang dari 0,05.

Tabel 3. Uji validitas dan reliabilitas.

\begin{tabular}{clccc}
\hline & Item & KMO-MSA & Sig. & Cronbach's Alpha \\
\hline X1 & Kemampuan & 0.562 & 0.000 & 0.631 \\
X2 & Kepribadian & 0.587 & 0.010 & 0.619 \\
X3 & Motivasi & 0.657 & 0.000 & 0.756 \\
X4 & Konten pelatihan & 0.641 & 0.000 & 0.700 \\
X5 & Metode pelatihan & 0.726 & 0.000 & 0.664 \\
X6 & Dukungan rekan Kerja & 0.667 & 0.000 & 0.744 \\
X7 & Dukungan atasan & 0.714 & 0.000 & 0.825 \\
X8 & Komitmen organisasi & 0.671 & 0.000 & 0.722 \\
X9 & Durasi pelatihan & 0.632 & 0.010 & 0.629 \\
X10 & Penyelenggara pelatihan & 0.631 & 0.000 & 0.712 \\
Y & Pencapaian OEE & 0.664 & 0.000 & 0.697 \\
\hline
\end{tabular}

Artinya semua variabel valid dan bisa dianalisis lebih lanjut. Sedangkan untuk pengukuran reliabilitas menggunakan Alpha Cronbach, seluruh nilainya berada di atas angka 0.6, yang mengindikasikan bahwa semua variabel reliabel dan bisa untuk dilakukan analisis lebih lanjut.

\subsection{Analisis Korelasi.}

Berdasarkan asumsi hubungan yang diusulkan antara variabel pelatihan dan pencapaian Kinerja Maintenance (OEE), pengujian pengukuran hubungan antar variabel menggunakan korelasi Pearson. Ukuran signifikansi dari nilai korelasi menggunakan tabel. Dengan jumlah responden sebanyak 120 , maka nilai $r$ tabel yang didapat adalah 0.178 pada tingkat signifikansi 0.05. Hubungan keseluruhan diantara semua variabel ditampilkan dalam tabel 4 matrik korelasi. 
Tabel 4. Matrik korelasi.

\begin{tabular}{|c|c|c|c|c|c|c|c|c|c|c|c|}
\hline \multicolumn{12}{|c|}{ Pearson Correlations Matrix } \\
\hline & $\mathrm{X} 1$ & $\mathrm{X} 2$ & $\mathrm{X} 3$ & $\mathrm{X} 4$ & X5 & X6 & $\mathrm{X7}$ & $\mathrm{X} 8$ & X9 & $\mathrm{X} 10$ & Y \\
\hline $\mathrm{X} 1$ & 1 & & & & & & & & & & \\
\hline $\mathrm{X} 2$ & 0.068 & 1 & & & & & & & & & \\
\hline $\mathrm{X} 3$ & $.539^{* *}$ & $.294^{* *}$ & 1 & & & & & & & & \\
\hline $\mathrm{X} 4$ & $.290^{* *}$ & 0.156 & $.380^{* * *}$ & 1 & & & & & & & \\
\hline $\mathrm{X} 5$ & 0.177 & 0.148 & $.269^{* *}$ & $.447^{* *}$ & 1 & & & & & & \\
\hline X6 & 0.177 & $.547^{* *}$ & $.534^{* *}$ & $.416^{* *}$ & $.312^{* *}$ & 1 & & & & & \\
\hline $\mathrm{X} 7$ & $.483^{* *}$ & $.519^{* *}$ & $.639^{* *}$ & $.205^{*}$ & 0.102 & $.419^{* *}$ & 1 & & & & \\
\hline $\mathrm{X} 8$ & $.378^{* *}$ & $.352^{* *}$ & $.649^{* *}$ & $.466^{* *}$ & 0.096 & $.345^{* *}$ & $.619^{* *}$ & 1 & & & \\
\hline X9 & $.243^{* *}$ & -0.136 & -0.083 & 0.106 & $.275^{* *}$ & -0.042 & -0.02 & -0.067 & 1 & & \\
\hline $\mathrm{X} 10$ & -0.095 & -0.121 & -0.111 & 0.13 & 0.011 & -0.081 & $-.228^{*}$ & $-.263^{* *}$ & $.256^{* *}$ & 1 & \\
\hline Y & -0.047 & $.321^{* *}$ & $.375^{* *}$ & $.249^{* *}$ & 0.143 & 0.114 & 0.09 & $.276^{* *}$ & $.225^{*}$ & -0.028 & 1 \\
\hline
\end{tabular}

**. Correlation is significant at the 0.01 level (2-tailed).

*. Correlation is significant at the 0.05 level (2-tailed).

Matriks korelasi Pearson yang ditunjukkan oleh table 4 menunjukkan bahwa Lima variabel dari faktor pelatihan mempunyai hubungan yang signifikan terhadap kinerja maintenance. Pada tabel 5, hubungan terkuat ditemukan antara variabel motivasi (X3) terhadap pencapaian OEE ( $\gamma=$ $0.375, \mathrm{p}<0.01$ ). Variabel kepribadian (X2) juga mempunyai hubungan yang kuat terhadap pencapaian OEE $(\gamma=0.321, p<0.01)$. Secara berurutan berdasarkan tingkat signifikansi faktor pelatihan terhadap pencapaian OEE adalah variabel (X8) Komitmen Organisasi $(\gamma=0.276$, $p<$ $0.01)$, variabel (X4) Konten pelatihan $(\gamma=0.249, p<0.01)$, variabel (X9) Durasi pelatihan $(\gamma=$ $0.225, \mathrm{p}<0.01$ ). Sedangkan tiga variabel lain mempunyai hubungan yang positif namun tidak signifikan adalah variabel (X5) Metode pelatihan ( $\gamma=0.143)$, variabel (X7) Dukungan rekan kerja $(\gamma=0.09)$ dan variabel (X7) Dukungan atasan. Sisanya mempunyai hubungan negatif yaitu variabel $(X 1)$ kemampuan $(\gamma=-0.047)$ dan terakhir variabel penyelenggara pelatihan $(\gamma=-0.028)$.

\subsection{Analisis regresi.}

Untuk menyelidiki faktor pelatihan yang menentukan keberhasilan kinerja maintenance, korelasi yang signifikan uji[22] divalidasi melalui "Analisis Regresi Berganda" [22]. Hali ini seperti yang digambarkan pada tabel 5. Sebagaimana ditunjukkan oleh tabel 5, hasil analisis regresi menunjukkan pelatihan merupakan faktor yang penting dalam menentukan kinerja maintenance.

Tabel 5. Hasil analisis regresi. 


\begin{tabular}{crrrrr}
\hline \multirow{2}{*}{ Model } & \multicolumn{2}{c}{$\begin{array}{c}\text { Unstandardized } \\
\text { Coefficients }\end{array}$} & $\begin{array}{c}\text { Standardized } \\
\text { Coefficients }\end{array}$ & \multirow{2}{*}{$\mathrm{t}$} & Sig. \\
\cline { 2 - 4 } & \multicolumn{1}{c}{ B } & Std. Error & Beta & & \\
\hline 1 & 11.879 & 1.813 & & 6.551 & 0.000 \\
(Constant) & & & & & \\
X1 & -0.712 & 0.091 & -0.547 & -7.798 & 0.000 \\
X2 & 0.925 & 0.097 & 0.682 & 0.492 & 0.000 \\
X3 & 0.931 & 0.076 & 1.154 & 12.209 & 0.000 \\
X4 & 0.379 & 0.074 & 0.380 & 5.087 & 0.000 \\
X5 & -0.188 & 0.049 & -0.251 & -3.873 & 0.000 \\
X6 & -0.552 & 0.071 & -0.590 & -7.747 & 0.000 \\
X7 & -0.268 & 0.048 & -0.472 & -5.610 & 0.000 \\
X8 & -0.214 & 0.095 & -0.196 & -2.254 & 0.026 \\
X9 & -0.610 & 0.063 & 0.598 & 9.714 & 0.000 \\
X10 & -0.348 & 0.076 & -0.275 & -4.591 & 0.000 \\
\hline
\end{tabular}

Keterangan: Variabel bebas: faktor pelatihan; variabel terikat: OEE

Nilai R Square $=0.714 ; \mathrm{F}=27.233 ; \mathrm{N}=120 ;$ Sig. $\mathrm{F}=0.000$

$\mathrm{X} 1$ (Kemampuan) mempunyai sig. 0.000, X2 (Kepribadian) nilai sig. 0.000, X3 (Motivasi) sig. 0.000, X4 (Konten Pelatihan) sig. 0.000, X5 (Metode Pelatihan) sig. 0.000, X6 (Dukungan Rekan Kerja) sig. 0.000, X7 (Dukungan Atasan) sig. 0.000, X8 (Komitmen Organisasi) sig. 0.026, X9 (Durasi Pelatihan) sig. 0.000, dan terakhir X10 (Penyelenggara Pelatihan) mempunyai sig. 0.000. Ini artinya semua faktor pelatihan secara signifikan berpengaruh terhadap kinerja maintenance. Berdasarkan output hasil perhitungan pada Model Summary regresi didapatkan nilai R Square sebesar 0.714 . Hal ini mengandung arti bahwa seluruh variabel pelatihan (X1, X2, X3, X4, X5, X6, $\mathrm{X} 7, \mathrm{X} 8, \mathrm{X} 9$, dan X10) secara simultan berpengaruh terhadap variabel kinerja maintenance (Y) sebesar $71.4 \%$. Persentase koefisien determinasi sebesar $71.4 \%$ tersebut dirasa sudah cukup untuk menunjukkan bahwa penelitian ini sudah bisa diterima, karena menurut Walpole et al. [22], dalam penelitian yang berhubungan dengan behavioral scientist, koefisien determinasi paling tidak di angka minimal 70\%.

\section{Simpulan}

Penelitian ini bertujuan untuk mengetahui seberapa besar pengaruh faktor transfer pelatihan dalam maintenance terhadap efektifitas kinerja maintenance. Dengan mengetahui faktor-faktor mana saja yang paling dominan berpengaruh terhadap kinerja maintenance, organisasi akan lebih mudah menerapkan tahapan dalam proses perencanaan dan implementasi pelatihan, sehingga hasil pelatihan yang dilakukan benar-benar memberikan dampak positif terhadap kinerja maintenance. Hasil penelitian ini bisa digunakan sebagai referensi bagi departemen maintenance dalam sebuah organisasi untuk menentukan faktor pelatihan apa saja yang menjadi prioritas terlebih dahulu ketika organisasi belum dapat melakukan implementasi penerapan faktor pelatihan secara bersamaan.

\section{Daftar Pustaka}

[1] A. Parida and U. Kumar, "Maintenance performance measurement (MPM): Issues and challenges," J. Qual. Maint. Eng., vol. 12, no. 3, pp. 239-251, 2006.

[2] K. Fraser, H. H. Hvolby, and T. L. B. Tseng, "Reliability paper Maintenance management models: A study of the published literature to identify empirical evidence a greater 
practical focus is needed," Int. J. Qual. Reliab. Manag., vol. 32, no. 6, pp. 635-664, 2015.

[3] C. P. Au-Yong, A. S. Ali, and F. Ahmad, "Optimising maintenance cost performance with skilled technicians," Struct. Surv., vol. 32, no. 3, pp. 238-245, 2014.

[4] Z. Z. Z. Fatoni and R. Nurcahyo, "Impact of training on maintenance performance effectiveness," Proc. Int. Conf. Ind. Eng. Oper. Manag., vol. 2018, no. JUL, pp. 619-628, 2018.

[5] C. Golam Hossan, Employee Training and Development, 4th edition20071Raymond A. Noe. Employee Training and Development, 4th edition . New York: McGraw-Hill Irwin 2008. xV + 536 pp., ISBN: hardback US\$79.99, vol. 30, no. 12. 2007.

[6] R. Ahmad and S. Kamaruddin, "A review of condition-based maintenance decision-making," Eur. J. Ind. Eng., vol. 6, no. 5, pp. 519-541, 2012.

[7] J. Tätilä, P. Helkiö, and J. Holmström, "Exploring the performance effects of performance measurement system use in maintenance process," J. Qual. Maint. Eng., vol. 20, no. 4, pp. 377-401, 2014.

[8] A. Rastegari and A. Salonen, "Strategic maintenance management: Formulating maintenance strategy," Int. J. COMADEM, vol. 18, no. 1, pp. 5-14, 2015.

[9] SERDAR DALKILIC, "Improving aircraft safety and reliability by aircraft maintenance technician training," 2017.

[10] M. R. Salah, "The Impact of Training and Development on Employees Performance and Productivity 'A case Study of Jordanian Private Sector transportation companies located in the Southern region of Jordan. A particular reference is made to the Govern ate of Maan' .," Int. J. Manag. Sci. Bus. Res., vol. 05, no. 07, pp. 36-57, 2016.

[11] F. D. Kum , R. Cowden, and A. M. Karodia, "The Impact of Training and Development on Employee Performance: A Case Study of Escon Consulting," Singaporean J. Bus. , Econ. Manag. Stud., vol. 3, no. 3, pp. 72-105, 2014.

[12] R. de L. Baldam, G. M. Fiorot, R. M. G. da Silva, T. R. Pitanga, and V. A. Vieira, "Atendendo à alta demanda de treinamento nas organizações e reduzindo os custos," RACE - Rev. Adm. Contab. e Econ., vol. 17, no. 1, pp. 129-150, 2018.

[13] B. D. Blume, J. K. Ford, T. T. Baldwin, and J. L. Huang, "Transfer of training: A meta-analytic review," J. Manage., vol. 36, no. 4, pp. 1065-1105, 2010.

[14] I. Nikandrou, V. Brinia, and E. Bereri, "Trainee perceptions of training transfer: An empirical analysis," J. Eur. Ind. Train., vol. 33, no. 3, pp. 255-270, 2009.

[15] H. Gouda, "Training programs: The relationship between learning in the workplace and organizational success," Int. J. African Asian Stud., vol. 11, pp. 84-92, 2015.

[16] B. S. Bell, S. I. Tannenbaum, J. Kevin Ford, R. A. Noe, and K. Kraiger, "100 years of training and development research: What we know and where we should go," J. Appl. Psychol., vol. 102, no. 3, pp. 305-323, 2017.

[17] A. Jain, R. S. Bhatti, and H. Singh, "OEE enhancement in SMEs through mobile maintenance: A TPM concept," Int. J. Qual. Reliab. Manag., vol. 32, no. 5, pp. 503-516, 2015.

[18] E. J. Clements, V. Sonwaney, and R. K. Singh, "Measurement of overall equipment effectiveness to improve operational efficiency," Int. J. Process Manag. Benchmarking, vol. 8, no. 2, p. 246, 2018.

[19] A. M. Nasurdin, M. Jantan, W. W. Peng, and T. Ramayah, "Influence of Employee Involvement in Total Productive Maintenance Practices on Job Characteristics: The Malaysian Scenario," Gadjah Mada Int. J. Bus., vol. 7, no. 3, p. 287, 2005.

[20] A. H. C. Tsang, A. K. S. Jardine, and H. Kolodny, "Measuring maintenance performance: A 
holistic approach," Int. J. Oper. Prod. Manag., vol. 19, no. 7, pp. 691-715, 1999.

[21] Maung, "Influence of Organizational Work Environment on Transfer of Training in Banking Sector," South East Asia J. Contemp. Business, Econ. Law, vol. 4, no. 1, pp. 35-41, 2014.

[22] A. R. Bahtiar, "Analisis Faktor-Faktor yang mempengaruhi Keberhasilan Program Pelatihan," Prodi Magister Manaj., vol. 11, no. 02, pp. 7-8, 2018.

[22] Walpole, R.E., Myers, R.H., Myers, R.L. \& Ye, K, "Probability \& Statistics for Engineers \& Scientists 9th. Edition. Boston: Pearson education, 2012. 